\title{
Effectiveness of cidofovir intralesional treatment in recurrent respiratory papillomatosis
}

\author{
Małgorzata Wierzbicka $\cdot$ Joanna Jackowska $\cdot$ \\ Anna Bartochowska • Agata Józefiak • \\ Witold Szyfter · Witold Kędzia
}

Received: 8 February 2011 / Accepted: 29 March 2011 / Published online: 26 April 2011

(C) The Author(s) 2011. This article is published with open access at Springerlink.com

\begin{abstract}
To present the results of recurrent respiratory papillomatosis (RRP) treatment with surgical excision and adjuvant anti-viral cidofovir intralesional use and to examine the correlation between the cidofovir effectiveness and the patient previous history of multiple larynx procedures, age, extension of lesion and dose. 32 patients with laryngeal papillomas were treated with cidofovir in our Department between I.2009 and I.2011. The number of previous RRP debulking procedures ranged from 1 to 100 . The intensity of papillomatosis differed from one anatomic site and moderate growth to four or five localizations with heavy extension. The number of injections per patient varied from 1 to 7 , and the total volume of $5 \mathrm{mg} / \mathrm{ml}$ solution varied from 2 to $33 \mathrm{ml}$. The injections were combined with laser debulking of the lesions. In disperse papillomata, the injections were administered in particular anatomical sites in 4-6 weeks intervals, in massive lesions injections were repeated in the same anatomical site in $2-4$ weeks. Complete remission was observed in 18 out of 32 patients. 13 patients showed remission in a place of cidofovir injection. One patient did not react to the drug. In four patients, new changes in injection places appeared. In two patients,
\end{abstract}

Approval of Bioethics Committee of University of Medical Sciences in Poznań.

M. Wierzbicka · J. Jackowska · A. Bartochowska $\cdot$ W. Szyfter $(\bowtie)$ Department of Otolaryngology,

Poznań University of Medical Sciences, Przybyszewskiego Street 49, 60-355 Poznań, Poland e-mail: otosk2@amp.edu.pl

\section{A. Józefiak · W. Kędzia}

Molecular Diagnostics Laboratory of Uterine Cervix

Patophysiology Division, Poznań University of Medical Sciences,

Obstetrics and Gynecology Hospital, Poznań, Poland hepatic toxic side effects were observed. Intralesional cidofovir injection has been shown to be an effective and safe therapy for laryngeal papillomatosis and should be considered in those patients who experienced disease relapse.

Keywords Respiratory papillomatosis $\cdot \mathrm{HPV} \cdot$ Cidofovir

\section{Introduction}

Recurrent respiratory papillomatosis (RRP), predominantly affecting the larynx and trachea, is caused by human papilloma virus (HPV). The condition is extremely difficult to treat and patients usually undergo multiple surgical procedures and are given toxic systemic medications to control their disease (acyclovir, ribavirin, isotretinoin, indol-3-carbinol, and interferon [1]). Until recently, treatment has focused on removal of the lesions with ablation of the root of the papilloma to prevent regrowth. Since the popularization of the $\mathrm{CO}_{2}$ laser for laryngeal surgery in the 1970s, repeated laser ablation has been the mainstay of therapy [1], with some patients undergoing microlaryngoscopy with laser treatment monthly or even more frequently. However, this method carries risks of thermal injury, web formation, scarring, poor voice quality and, unfortunately, there is a high rate of recurrence as lesions regrow at the sites of ablation and other develop in previously seemingly uninvolved areas. Administration of adjuvant antiviral agents is also associated with numerous side effects $[1,2]$.

Direct intralesional injection of cidofovir has found increasing use as a primary treatment for RRP in both children and adults [3, 4]. Cidofovir, an antiviral drug, [(S)-1-(3-hydroxy-2-phosphonylmethoxypropyl) cytosine or HPMPC], a nucleoside analog, is approved by the FDA 
(Food and Drug Administration) for intravenous use to treat cytomegalovirus retinitis in patients with acquired immunodeficiency syndrome. Even though it has not been approved for topical or intralesional use, cidofovir has also been used to treat several cutaneous and mucosal viral lesions $[5,6]$. The first report of successful intralesional injection of cidofovir directly into the respiratory papillomas was described in 1995 by Van Cutsem et al. [7] in a 69-year-old patient with hypopharyngeal and esophageal RRP. Recently, severe side effects of intralesional cidofovir injections have been examined and described: single case of squamous cell carcinoma arising from squamous papilloma [8], association between use of cidofovir and dysplastic mucosa changes [9], and induction of alterations in gene expression associated with malignant transformation [10, 11]. Some investigators dealing with RRP have suggested the 3-5\% potential for malignant transformation of these viral-associated lesions [12], while Lee and Rosen [13] showed a $23 \%$ incidence of malignant transformation with six laryngeal cancers out of 26 RRP patients. Gupta et al. [14], on the basis of pathologic data from 13 patients, drew the strong suggestion that spontaneous dysplasia is relatively common in the setting of RRP; however, the prognostic significance of this finding persists unknown and intralesional cidofovir therapy does not correlate with worsening dysplastic progression.

The aim of the study was to present the results of RRP treatment with surgical excision and adjuvant anti-viral cidofovir intralesional use and to examine the correlation between the cidofovir effectiveness and the patient previous history of multiple larynx procedures, age, extension of lesion and dose.

\section{Materials and methods}

Between January 2009 and January 2011, 32 patients were treated for RRP in the Department of Otolaryngology and Laryngological Oncology in Poznań. They were from 6- to 80-year old, mean age was 33 years. In the study group, there were 13 females and 19 males. Localization and extent of papillomata and the epidemiological data are shown in Tables 1 and 2. Papillomas volume was described according to Dikkers scale [15].

The mechanical removal or laser ablation had been a main method of treatment for recurrent laryngeal papillomas in the Department of Otolaryngology and Laryngological Oncology for many years. Since 2009 new pharmacological treatment has been additionally introduced-intralesional cidofovir injections. In 32 patients removal of papillomas using the Kleinsasser microlaryngoscope was performed and all patients had intralesional injections of cidofovir. Before the first cidofovir administration majority of patients had undergone several mechanical/laser treatment procedures due to the recurrent nature of disease (from 2 to more than 100) (Table 1). Cidofovir injections were given to the areas previously cleaned mechanically or with the laser. In anterior commissure, the drug was administered under the stroma of papillomas due to high risk of adhesion after mechanical treatment. Injections under control of an operating microscope were provided within the vocal fold into the subepithelial space of Reinke, subepithelially to the vestibular fold, or supraglottic area. Subepithelial layer of the hypopharynx and the entrance of the esophagus were also injected. Single drug dose ranged from 1 to $12 \mathrm{ml}$, average was $3 \mathrm{ml}$. Maximum volume of $12 \mathrm{ml}$ was used in only one case to inject three different anatomical regions of the larynx, hypopharynx, and entrance of the esophagus (No. 3). The minimal $1 \mathrm{ml}$ dose was applied to the limited papilloma in one vocal fold. None of the patients was given more than $3 \mathrm{mg}$ of cidofovir per $1 \mathrm{~kg}$ of body weight, what is in line with international recommendations for the use of the drug [29]. Combined treatment of papillomas including mechanical removal and cidofovir injections in individual patients were repeated from 1 to 7 times. It depended on the response to the first injection and the occurrence of potential side effects. The total dose of drug ranged from 2 to $33 \mathrm{ml}$ and was extended in time to 16 months (Table 3 ). The follow-up period currently ranges from 2 to 21 months (Table 3). Each patient who had undergone cidofovir treatment was examined to diagnose any organ complications. Morphology with blood smear, urea, creatinine, ALT, AST, and bilirubin levels was checked (before the treatment and 1 day after the injection).

\section{Results}

Papillomatous lesions were mostly located in the vocal folds, anterior commissure, and vestibular folds. In 11 patients, the disease involved aryepiglottic folds and supraglottic area. In two patients, papillomatosis occurred in the posterior commissure (No. 6 and 29). Hypopharynx and arytenoids were occupied in five patients (No. 3, 4, 9, 27, and 28). Papillomas of the entrance of the esophagus were diagnosed in one patient (No. 3). In that patient papillomas covered the entire hypopharynx, larynx except of the laryngeal surface of the epiglottis, supraglottic area, and the entrance of the esophagus. The trachea was involved in one patient with previous tracheostomy (No. 6). Epiglottis was occupied in seven patients (No. 3, 5, 23, 24, 28, 30, and 32). Diffuse disease was observed in two patients: in the first one changes occurred in three anatomical regions (No. 3) and in the second patient in all floors of the larynx, trachea, and supraglottic area up to the fourth ring of the trachea (No. 6). 
Table 1 Patient data-age, gender, prior treatment

\begin{tabular}{|c|c|c|c|c|c|}
\hline $\begin{array}{l}\text { Table } 1 \text { Patient data-age, } \\
\text { gender, prior treatment }\end{array}$ & Patient & Gender & $\begin{array}{l}\text { Age at the beginning of } \\
\text { cidofovir therapy (years) }\end{array}$ & $\begin{array}{l}\text { Number of mechanical procedures } \\
\text { before cidofovir injections }\end{array}$ & $\begin{array}{l}\text { Number of prior } \mathrm{CO}_{2} \\
\text { laser procedures }\end{array}$ \\
\hline & 1 & $\mathrm{~m}$ & 9 & 5 & 6 \\
\hline & 2 & $\mathrm{f}$ & 24 & 0 & 2 \\
\hline & 3 & $\mathrm{f}$ & 16 & 2 & 7 \\
\hline & 4 & $\mathrm{~m}$ & 24 & 0 & 2 \\
\hline & 5 & $\mathrm{f}$ & 30 & 0 & 2 \\
\hline & 6 & $\mathrm{~m}$ & 21 & 100 & 3 \\
\hline & 7 & $\mathrm{~m}$ & 30 & 5 & 1 \\
\hline & 8 & $\mathrm{f}$ & 38 & 3 & 1 \\
\hline & 9 & $\mathrm{f}$ & 44 & 40 & 2 \\
\hline & 10 & $\mathrm{~m}$ & 27 & 0 & 4 \\
\hline & 11 & $\mathrm{~m}$ & 33 & 100 & 4 \\
\hline & 12 & $\mathrm{~m}$ & 43 & 0 & 2 \\
\hline & 13 & $\mathrm{~m}$ & 80 & 10 & 6 \\
\hline & 14 & $\mathrm{~m}$ & 21 & 0 & 1 \\
\hline & 15 & $\mathrm{~m}$ & 60 & 0 & 2 \\
\hline & 16 & $\mathrm{f}$ & 61 & 30 & 5 \\
\hline & 17 & $\mathrm{~m}$ & 22 & 0 & 2 \\
\hline & 18 & $\mathrm{~m}$ & 33 & 10 & 3 \\
\hline & 19 & $\mathrm{f}$ & 17 & 2 & 1 \\
\hline & 20 & $\mathrm{~m}$ & 50 & 1 & 1 \\
\hline & 21 & $\mathrm{~m}$ & 7 & 5 & 5 \\
\hline & 22 & $\mathrm{f}$ & 30 & 2 & 2 \\
\hline & 23 & $\mathrm{f}$ & 33 & 1 & 3 \\
\hline & 24 & $\mathrm{~m}$ & 23 & 4 & 3 \\
\hline & 25 & $\mathrm{~m}$ & 78 & 3 & 2 \\
\hline & 26 & $\mathrm{~m}$ & 31 & 6 & 2 \\
\hline & 27 & $\mathrm{f}$ & 33 & 3 & 1 \\
\hline & 28 & $\mathrm{f}$ & 18 & 3 & 1 \\
\hline & 29 & $\mathrm{f}$ & 16 & 2 & 1 \\
\hline & 30 & $\mathrm{f}$ & 68 & 30 & 6 \\
\hline & 31 & $\mathrm{~m}$ & 30 & 4 & 2 \\
\hline & 32 & $\mathrm{~m}$ & 6 & 4 & 3 \\
\hline & Mean & & 33 & 12 & 3 \\
\hline & Median & & 30 & 3 & 2 \\
\hline$m$ male, $f$ female & Modus & & 30 & 0 & 2 \\
\hline
\end{tabular}

$m$ male, $f$ female

The efficiency of cidofovir treatment in the Department of Otolaryngology and Laryngological Oncology was evaluated on the basis of relapse of the papillomas. After 4 weeks, each patient underwent laryngological examination and, if the papillomas were present, was qualified for direct laryngoscopy and repeated cidofovir injection. A complete remission occurred in 18 patients. Other 13 patients had complete remission in the injection site, but in places that were not injected, persistent lesions were observed. One patient did not react to the drug (No. 32). In four patients, new changes in injection places appeared (No. 3, 11, 16, and 32) (Table 3). The correlation between extension of lesions and amount of drug was substantial but not statistically significant.

None of the patients had a local complication. All of them were easily extubated a few minutes after microlaryngoscopy. Twenty-four hours after cidofovir injection no laryngeal edema or inflammatory changes occurred. One patient (No. 3) who had the most extensive lesions at presentation and received a dose of $20 \mathrm{ml}$ of drug in 10 months developed the whitish cloudiness of the hypopharynx epithelium. Systemic side effects were observed in three patients (No. 1, 5, and 16). A 9-year-old boy had a weakness and diarrhea for about 4 days (No. 1). However, he 
Table 2 Clinical data-localization and extent of papillomatous lesions before cidofovir treatment

\begin{tabular}{|c|c|c|c|c|c|c|c|c|c|c|c|}
\hline \multirow[t]{2}{*}{ Patient } & \multirow[t]{2}{*}{ Vestibule } & \multirow[t]{2}{*}{ Arytenoid } & \multirow{2}{*}{$\begin{array}{l}\text { Aryepiglottic } \\
\text { folds }\end{array}$} & \multirow[t]{2}{*}{ Epiglottis } & \multicolumn{2}{|c|}{ Glottis } & \multirow{2}{*}{$\begin{array}{l}\text { Anterior } \\
\text { commisure }\end{array}$} & \multirow{2}{*}{$\begin{array}{l}\text { Posterior } \\
\text { commisure }\end{array}$} & \multirow{2}{*}{$\begin{array}{l}\text { Subglottis + } \\
\text { trachea }\end{array}$} & \multirow[t]{2}{*}{ Hypopharynx } & \multirow[t]{2}{*}{ Esophagus } \\
\hline & & & & & Left & Right & & & & & \\
\hline 1 & & & & & & 1 & 2 & & & & \\
\hline 2 & 1 & & & & 1 & 1 & 1 & & & & \\
\hline 3 & 1 & 3 & 1 & 1 & & 1 & & & & 2 & 3 \\
\hline 4 & 1 & 2 & & & 1 & & 1 & & & & \\
\hline 5 & & & 1 & 2 & & & & & & & \\
\hline 6 & & & & & & & & 1 & 3 & & \\
\hline 7 & & & & & 1 & 2 & 2 & & & & \\
\hline 8 & & & & & & & 2 & & & & \\
\hline 9 & 2 & 1 & & & 1 & & & & & & \\
\hline 10 & & & & & 2 & & 1 & & & & \\
\hline 11 & 2 & & & & 3 & 3 & & & 1 & & \\
\hline 12 & & & 1 & & 2 & 2 & 3 & & 3 & & \\
\hline 13 & & & & & 1 & 2 & & & & & \\
\hline 14 & 1 & & & & & 2 & 1 & & & & \\
\hline 15 & 1 & & & & & 3 & & & & & \\
\hline 16 & 2 & & 1 & & 1 & 1 & 2 & & & & \\
\hline 17 & & & & & & & 2 & & & & \\
\hline 18 & 1 & & & & 2 & 2 & 1 & & & & \\
\hline 19 & & & & & & 3 & 2 & & & & \\
\hline 20 & & & & & 1 & 1 & & & & & \\
\hline 21 & 2 & & & & 1 & 1 & & & & & \\
\hline 22 & & & & & & 2 & & & 2 & & \\
\hline 23 & 2 & & 1 & 3 & & 3 & 3 & & 2 & & \\
\hline 24 & 2 & & & 1 & 3 & 3 & 2 & & 1 & & \\
\hline 25 & 2 & & & & 2 & 2 & & & 1 & & \\
\hline 26 & 2 & & & & & & & & & & \\
\hline 27 & & 2 & & & 2 & & 2 & & & & \\
\hline 28 & & 3 & & 3 & 3 & & 2 & & 2 & 1 & \\
\hline 29 & & & & & 3 & 2 & & 3 & & & \\
\hline 30 & 2 & & & 3 & 3 & 2 & 3 & & 2 & & \\
\hline 31 & 2 & & & & & 1 & & & 2 & & \\
\hline 32 & 3 & & & 1 & 3 & 3 & 2 & & & & \\
\hline
\end{tabular}

Grading according to Dikkers scale: 1 sessile papilloma (unifocal or multifocal), 2 exophytic papilloma (unifocal), 3 exophytic papilloma (multifocal) [15]

additionally suffered from a Gilbert's syndrome, and the symptoms could have been associated with the defect in detoxification of the drug. Two other patients (30- and 61year old) had ALT and AST levels 3-fold increased 1 day after the injection (No. 5 and 16) - the values were within normal limits after 6 weeks of liver diet. The occurrence of complications was not related to the drug dose. None of the patients had skin changes, high body temperature, abnormal blood morphology, changed kidney, and coagulation parameters. Patients did not complain of breathing or swallowing problems.
The relapse-free time currently ranges from 3 to 21 months (Table 3 ).

\section{Discussion}

Recurrent RRP is a rare, severe airway management problem occurring in both children and adults, with 2-fold more often juvenile-onset [16-18]. Multiple investigators have shown that use of cidofovir for RRP markedly decreases the frequency and severity of local disease recurrence [19]. 
Table 3 Results of treatment

\begin{tabular}{|c|c|c|c|c|c|c|}
\hline Patient & $\begin{array}{l}\text { Number of cidofovir } \\
\text { injections }\end{array}$ & $\begin{array}{l}\text { Cumulative } \\
\text { dose (ml) }\end{array}$ & $\begin{array}{l}\text { Period of } \\
\text { injections (months) }\end{array}$ & $\begin{array}{l}\text { Response to } \\
\text { treatment }\end{array}$ & $\begin{array}{l}\text { Current } \\
\text { status }\end{array}$ & $\begin{array}{l}\text { Relapse-free } \\
\text { time (months) }\end{array}$ \\
\hline 1 & 4 & 9 & 16 & $\mathrm{CR}$ & Free & 8 \\
\hline 2 & 2 & 4 & 3 & $\mathrm{CR}$ & Free & 21 \\
\hline 3 & 6 & 33 & 14 & $\mathrm{CR}$ & Free & 7 \\
\hline 4 & 3 & 12 & 16 & PR & $\mathrm{RD}$ & \\
\hline 5 & 1 & 5 & 1 & CR & Free & 21 \\
\hline 6 & 3 & 7 & 2 & CR & Free & 19 \\
\hline 7 & 1 & 3 & 1 & $\mathrm{CR}$ & Free & 19 \\
\hline 8 & 1 & 2 & 1 & $\mathrm{CR}$ & Free & 6 \\
\hline 9 & 3 & 6 & 12 & PR & $\mathrm{RD}$ & \\
\hline 10 & 4 & 8 & 6 & $\mathrm{CR}$ & Free & 13 \\
\hline 11 & 7 & 24.5 & 16 & PR & $\mathrm{RD}$ & \\
\hline 12 & 3 & 8 & 12 & $\mathrm{CR}$ & Free & 7 \\
\hline 13 & 1 & 2 & 1 & $\mathrm{CR}$ & Free & 9 \\
\hline 14 & 1 & 2 & 1 & $\mathrm{CR}$ & Free & 17 \\
\hline 15 & 1 & 2 & 1 & $\mathrm{CR}$ & Free & 6 \\
\hline 16 & 2 & 8.5 & 6 & $\mathrm{CR}$ & Free & 4 \\
\hline 17 & 5 & 15 & 12 & $\mathrm{CR}$ & Free & 4 \\
\hline 18 & 3 & 10 & 11 & $\mathrm{CR}$ & Free & 4 \\
\hline 19 & 2 & 4 & 3 & PR & $\mathrm{RD}$ & \\
\hline 20 & 2 & 6 & 4 & PR & $\mathrm{RD}$ & \\
\hline 21 & 6 & 16 & 11 & PR & $\mathrm{RD}$ & \\
\hline 22 & 2 & 7.5 & 2 & PR & $\mathrm{RD}$ & \\
\hline 23 & 3 & 15 & 6 & $\mathrm{CR}$ & Free & 3 \\
\hline 24 & 3 & 7 & 2 & PR & $\mathrm{RD}$ & \\
\hline 25 & 2 & 5 & 2 & $\mathrm{CR}$ & Free & 7 \\
\hline 26 & 1 & 3 & 1 & $\mathrm{CR}$ & Free & 6 \\
\hline 27 & 1 & 2.5 & 1 & PR & $\mathrm{RD}$ & \\
\hline 28 & 1 & 7 & 1 & PR & $\mathrm{RD}$ & \\
\hline 29 & 1 & 3 & 1 & PR & $\mathrm{RD}$ & \\
\hline 30 & 1 & 6 & 1 & PR & $\mathrm{RD}$ & \\
\hline 31 & 1 & 2 & 1 & PR & $\mathrm{RD}$ & \\
\hline 32 & 2 & 9 & 7 & NR & $\mathrm{RD}$ & \\
\hline
\end{tabular}

$C R$ complete response, $P R$ partial response, $N R$ no response, $R D$ residual disease (response in the place of injection, next procedures planned)

Ideal medication should eliminate papillomatous lesions in a single setting. Although clinical experience suggests that repeated injections are necessary, the promise still remains that cidofovir may be more effective, with less risk than prior therapeutic options. The median treatment protocol presents injections of $2.5 \mathrm{mg} / \mathrm{ml}$ every 2 weeks in 12-month period. However, some surgeons have begun using even higher concentrations up to $5.0 \mathrm{mg} / \mathrm{ml}$. In 1998 , Snoeck et al. [20] reported successful treatment of 16 in 17 patients with severe lesions by intralesional injection of cidofovir in various volumes of $2.5 \mathrm{mg} / \mathrm{ml}$ in 2 -week intervals. Case control study published by McMurray et al. [21] showed the effectiveness of laser procedures with injection of cidofovir of $5 \mathrm{mg} / \mathrm{ml}$ concentration every 2 weeks. The highest mean cumulative dose reported in the literature is even $348 \mathrm{mg}$ [22]. Following the literature, we doubled the concentration of cidofovir we used to use to $5.0 \mathrm{mg} / \mathrm{ml}$ and performed injections in 2-6 weeks intervals, with mean 4-week break. The treatment schedule depended on the extension and localization of the lesions, with maximum total dose of $33 \mathrm{ml}$. The cumulative dose of cidofovir did never exceed $3 \mathrm{mg} / \mathrm{kg}$ [23].

The treatment results and successful RRP eradication, primarily thought to be excellent, nowadays have become ambiguous. In total number of 158 patients from different trials analyzed by Chadha et al. until the year 2007 [19], 
$57 \%$ of patients demonstrated complete resolution, $35 \%$ partial response, and $8 \%$ showed no improvement. According to Verguts et al. [24], cidofovir was a negative factor for remission. McMurray et al. [21] were unable to prove efficacy of cidofovir in RRP treatment. Chadha and James [19] concluded that there was insufficient evidence to support the efficiency of intralesional cidofovir in adults. The results observed by the authors were good, but not in all patients.

Because intralesional injection of cidofovir into the larynx is an off-label use of this medication, it may have complications and risks that were previously unknown. Although the nephrotoxic risks of systemic cidofovir administration are well reported, only a few publications describe the toxicity after local injection of this medication [25]. Broekema and Dikkers [22] enlisted other side effects of RRP cidofovir treatment: cutaneous rash, headache, local inflammatory response, vocal cord scarring, compromised airway, disorders of hematologic, and chemical parameters in blood. In the group examined by the authors one case of diarrhea, one of neutropenia, two temporary elevated levels of hepatic enzymes were observed. Surprisingly, larynx oedema was never noted even if high volume of solution ( $>5 \mathrm{ml}$ ) was injected.

Little is known of the histopathologic changes that cidofovir may induce in the laryngeal cartilage, muscle, ligaments, or mucosa near the areas injected. Due to high level of carcinogenicity of cidofovir shown in animal studies, RRP Task Force has published guidelines for clinicians administering this medicament [15, 26, 27]. In the literature ongoing, discussion about dysplastic propensity of topical cidofovir in human larynx carries on [14, 22]. Single cases of patients who developed dysplasia during intralesional treatment with cidofovir were reported [26, 28, 29]. Dysplasia was observed after an average period of 8 months after cidofovir treatment. Broekema and Dikkers [22] underline that dysplasia in cidofovir group occurred in $2.7 \%$ and this percentage is concurrent with the reported incidence of spontaneous malignant degeneration of RRP [20]. Gupta et al. [14] confirm that cidofovir treatment does not induce the progression of dysplasia. In our group, no dysplastic features in pathologic examination were observed in pre- and post-cidofovir samples during 21 months of follow-up, but of course the group is still under strict, regular control.

The main goals of RPP treatment are to relieve airway obstruction, improve voice quality, and facilitate remission. In our opinion, the schedule of treatment should include: mechanical/laser removal of the papillomatous lesions combined with cidofovir injection, control visits and indirect laryngoscopy (stroboscopy) in outpatient clinic every 4-6 weeks, immediate hospitalization, and another surgical procedure in suspicion of recurrence. The way of treatment should depend on the extension and localization of the lesions, the response to the first injection of cidofovir, and the occurrence of potential side effects. Maximum total dose of cidofovir should not exceed $3 \mathrm{mg} / \mathrm{kg}$. Due to high toxicity of cidofovir, we recommend checking laboratory parameters like morphology with blood smear, urea, creatinine, ALT, AST, and bilirubin levels before the treatment, 1 day and 4 weeks after the injection. All papillomas should be examined histopathologically to exclude any dysplastic features or malignant transformation.

\section{Conflict of interest None.}

Open Access This article is distributed under the terms of the Creative Commons Attribution Noncommercial License which permits any noncommercial use, distribution, and reproduction in any medium, provided the original author(s) and source are credited.

\section{References}

1. Goon P, Sonnex C, Jani P, Stanley M, Sudhoff H (2008) Recurrent respiratory papillomatosis: an overview of current thinking and treatment. Eur Arch Otorhinolaryngol 265(2):147-151

2. Tanna N, Sidell D, Joshi AS, Bielamowicz SA (2008) Adult intralesional cidofovir therapy for laryngeal papilloma: a 10-year perspective. Arch Otolaryngol Head Neck Surg 134(5):497-500

3. Bielecki I, Mniszek J, Cofała M (2009) Intralesional injection of cidofovir for recurrent respiratory papillomatosis in children. Int $\mathbf{J}$ Pediatr Otorhinolaryngol 73(5):681-684

4. Chung BJ, Akst LM, Koltai PJ (2006) 3.5-Year follow-up of intralesional cidofovir protocol for pediatric recurrent respiratory papillomatosis. Int J Pediatr Otorhinolaryngol 70(11):19111917

5. Gallagher TQ, Derkay CS (2009) Pharmacotherapy of recurrent respiratory papillomatosis: an expert opinion. Expert Opin Pharmacother 10(4):645-655

6. Gallagher TQ, Derkay CS (2008) Recurrent respiratory papillomatosis: update 2008. Curr Opin Otolaryngol Head Neck Surg 16(6):536-542

7. Van Cutsem E, Janssens J, Rutgeerts P, Vantrappen G, Snoeck R, Van Ranst M, Fiten P, Opdenakker G, de Clercq E, Geboes K (1995) Successful treatment of a squamous papilloma of the hypopharynx-esophagus by local injections of (S)-1-(3-hydroxy-2phosphonylmethoxypropyl)cytosine. J Med Virol 45(2):230-235

8. Lott DG, Krakovitz PR (2009) Squamous cell carcinoma associated with intralesional injection of cidofovir for recurrent respiratory papillomatosis. Laryngoscope 119(3):567-570

9. Sajan JA, Kerschner JE, Merati AL, Osipov V, Szabo S, Blumin JH (2010) Prevalence of dysplasia in juvenile-onset recurrent respiratory papillomatosis. Arch Otolaryngol Head Neck Surg 136(1):7-11

10. Donne AJ, Hampson L, He XT, Day PJ, Salway F, Rothera MP, Homer JJ, Hampson IN (2009) Potential risk factors associated with the use of cidofovir to treat benign human papillomavirusrelated disease. Antivir Ther 14(7):939-952

11. Donne AJ, Rothera MP, Homer JJ (2008) Scientific and clinical aspects of the use of cidofovir in recurrent respiratory papillomatosis. Int J Pediatr Otorhinolaryngol 72(7):939-944

12. Kimberlin DW, Malis DJ (2000) Juvenile onset recurrent respiratory papillomatosis: possibilities for successful antiviral therapy. Antiviral Res 45(2):83-93 
13. Lee AS, Rosen CA (2004) Efficacy of cidofovir injection for the treatment of recurrent respiratory papillomatosis. J Voice 18(4):551-556

14. Gupta HT, Robinson RA, Murray RC, Karnell LH, Smith RJ, Hoffman HT (2010) Degrees of dysplasia and the use of cidofovir in patients with recurrent respiratory papillomatosis. Laryngoscope 120(4):698-702

15. Dikkers FG (2006) Treatment of recurrent respiratory papillomatosis with microsurgery in combination with intralesional cidofovir-a prospective study. Eur Arch Otorhinolaryngol 263(5):440443

16. Hawkes M, Campisi P, Zafar R, Punthakee X, Dupuis A, Forte V, Ford-Jones EL (2008) Time course of juvenile onset recurrent respiratory papillomatosis caused by human papillomavirus. Pediatr Infect Dis J 27(2):149-154

17. Naiman AN, Ayari S, Nicollas R, Landry G, Colombeau B, Froehlich $P$ (2006) Intermediate-term and long-term results after treatment by cidofovir and excision in juvenile laryngeal papillomatosis. Ann Otol Rhinol Laryngol 115(9):667-672

18. Shehab N, Sweet BV, Hogikyan ND (2005) Cidofovir for the treatment of recurrent respiratory papillomatosis: a review of the literature. Pharmacotherapy 25(7):977-989

19. Chadha NK, James AL (2007) Antiviral agents for the treatment of recurrent respiratory papillomatosis: a systematic review of the English-language literature. Otolaryngol Head Neck Surg 136(6):863-869

20. Snoeck R, Wellens W, Desloovere C, Van Ranst M, Naesens L, De Clercq E, Feenstra L (1998) Treatment of severe laryngeal papillomatosis with intralesional injections of cidofovir [(S)-1-(3-hy- droxy-2-phosphonylmethoxypropyl)cytosine]. J Med Virol 54(3): 219-225

21. McMurray JS, Connor N, Ford CN (2008) Cidofovir efficacy in recurrent respiratory papillomatosis: a randomized, double-blind, placebo-controlled study. Ann Otol Rhinol Laryngol 117(7):477483

22. Broekema FI, Dikkers FG (2008) Side-effects of cidofovir in the treatment of recurrent respiratory papillomatosis. Eur Arch Otorhinolaryngol 265(8):871-879

23. Naiman AN, Roger G, Gagnieu MC, Bordenave J, Mathaut S, Ayari S, Nicollas R, Bour JB, Garabedian N, Froehlich P (2004) Cidofovir plasma assays after local injection in respiratory papillomatosis. Laryngoscope 114(7):1151-1156

24. Verguts MM, Genbrugge E, de Jong FI (2009) Treatment results in adult-onset recurrent respiratory papillomatosis. B-ENT $5(3): 137-141$

25. Derkay C (2009) Use of cidofovir for treatment of recurrent respiratory papillomatosis. Arch Otolaryngol Head Neck Surg 135(2):198-201

26. Dikkers FG (2008) Intralesional cidofovir does not increase the risk of laryngeal dysplasia or laryngeal carcinoma. Int J Pediatr Otorhinolaryngol 72(10):1581-1582

27. RRP Task Force Guidelines. http://www.rrpf.org/RRP_Task_ Cidofovir.html

28. Pudszuhn A, Welzel C, Bloching M, Neumann K (2007) Intralesional Cidofovir application in recurrent laryngeal papillomatosis. Eur Arch Otorhinolaryngol 264(1):63-70

29. Soma MA, Albert DM (2008) Cidofovir: to use or not to use? Curr Opin Otolaryngol Head Neck Surg 16(1):86-90 